\title{
Self- Care Knowledge and Practice for Patients with Permanent Stoma and their Effect on Their Quality of Life and Self Care Efficacy
}

\author{
Hanem F. Mohamed, RN, PhD ${ }^{1} \quad$ Seham A. Abd El-Hay, RN, PhD ${ }^{1} \quad$ Sabah M. Sharshor, RN, $\mathrm{PhD}^{2}$ \\ 1.Assistant Professor, Medical Surgical Nursing Department, Faculty of Nursing, Tanta University, Egypt \\ 2. Lecturer, Pediatric Nursing Department, Faculty of Nursing, Tanta University, Egypt
}

\begin{abstract}
Background: Quality of life (QOL) and self-care efficacy especially for patients with permanent stoma are importance. Addressing knowledge and self-care practice and their relationship with QOL is needed especially for patients in different age groups. This would serve as a base for developing a culturally competent educational intervention for these specific population. The aim of present study was to assess the level of knowledge and selfcare practice for patients with permanent stoma and its effect on their QOL and self-care efficacy. Methods: A descriptive correlational cross-sectional design was utilized to collect data from Clinical Oncology and Nuclear Medicine Department and its relevant outpatient's clinic of Tanta Main University Hospital and Outpatient's Clinic of General Surgical Department of Emergency Hospital at Tanta University. A convenience sampling of 140 adults and adolescents' patients with permanent stoma were interviewed. The study questionnaire included a self-reported checklist that include sociodemographic data, knowledge of stoma and stoma self-care practice that was developed by the researchers. A modified version of the Stoma Quality of Life Scale (SQOL) and Stoma self - Efficacy Scale were also utilized. Results: Majority of the adolescents were males, singles and in age group 16 to 21 . The main cause of stoma among adolescents was cancer, $90 \%$ had the operation within 6 months and 57\% reported having difficulty with self-care. Regarding adults, $67 \%$ were in age group 31 to $60,50 \%$ were married males, $47 \%$ were university graduates with a majority were working. Causes of stoma were mainly abdominal trauma, $46 \%$ were smokers, $57 \%$ had the operation within 6 months and 43\% reported having difficulty with self-care. Two thirds of adolescents and $41 \%$ of adults reported fair level of knowledge of stoma definition, causes, types, complication and risks. More than half of the adolescents reported fair knowledge and more than one third reported good knowledge regarding stoma pouch, appliance for stoma, criteria of changing pouch of stoma. Fifty-eight percent of the adults reported good knowledge and 27\% reported fair knowledge regarding same item. 64\% of the adolescents and $50 \%$ of adults reported fair knowledge of diet, fluids and activity. Knowledge of self-care practice was presented as fair among $50 \%$ of the adolescents and $43 \%$ of adults. Meanwhile, good level of knowledge was reported among $52.9 \%$ of adults and $28.6 \%$ of adolescents for the same item. Total QOL and all subscales except for sexual aspect were reported as fair with statistically significant association between both groups. Self-care efficacy was negative among majority adolescents and positive among most of the adults. Conclusion and recommendations: The current study provided an evidence of unsatisfactory level of knowledge and self-care practice among adolescents and adults patients with permanent stoma. Quality of life and self-efficacy were also alarming. There is a need for culturally competent intervention with larger sample and qualitative methods of research to deeply explain this area.
\end{abstract}

Keywords: Stoma, self- Care, quality of life, self-care efficacy, adult, adolescent.

DOI: $10.7176 / \mathrm{JHMN} / 60-13$

Publication date:March $31^{\text {st }} 2019$

\section{Introduction}

Stoma is a surgical procedure to divert the physiological way of elimination through a temporary or permanent opening (Racella et al. 2013; Bartle. et al., 2013). Stoma takes its name according to its location. Intestinal stoma classified as colostomy and ileostomy, and urostomy for diversion of the urinary stream (Sasaki et al., 2012). Stoma is performed for management of bowel dysfunction due to various causes that are not limited to cancer (Carlson et al., 2010; Marquis, et al., 2003). Many other causes include acute diverticulitis, trauma or injury, imperforate anus, partial or complete intestinal blockage, inflammatory bowel disease which manifest during childhood or adolescence for about 20-25\% of patients (Mohamed, et al., 2018; Taylor et al., 2012). Inflammatory bowel disease is the most common causes of the creation of stoma especially in adolescents (Grant et al., 2004). The American Cancer Society, 2017 reported that colorectal cancer is the third common cancer type and became the second cause of death worldwide (American Cancer Society, 2017). The number of patients performed stoma surgery is increasing with about one million people living in North America with permanent stoma, and more than 120,000 new stomas are performed each year (Putri, et al., 2018). According to the National Cancer Institute in Egypt, approximately 650,000 adults in Egypt currently have a stoma and about 3000 new surgeries are performed each year with colostomy (El Sayed et al., 2018). Also, approximately 2400 adolescent had undergone colostomy 
(National Cancer Institute, 2016).

Patients with stoma either adult or adolescents suffer physiological changes and psychological alteration (Abo Elfadl et al., 2013). Physical changes include loss of sphincter control, diarrhea, constipation, impaction of stool or excessive gases, skin irritation, problems with irrigation of colostomy and application of pouching system correctly, problems of leakage and presence of bad odor (De Sousa, et al., 2016). Psychological alterations are mainly fear, embarrassment, distress, low self-esteem, depression, negative emotions, and social isolation(Calvert, et al., 2012; Salomé, et al., 2014). These alterations result in negative impact on the patients' quality of life and self -efficacy (Pandey \& Dhungana, 2013, Cheng et al., 2013).

Adaptation to such big change in life is important as these patients needs to experience new behavior for selfmanagement and self-care. Successful adaptation of new behavior requires knowledge and skills and certain levels of self-efficacy to enhance quality of life (Bandura, 1977). To target education to patients with permanent stoma, it is important to assess their educational needs. Therefore, the aim of the current study was to assess the level of knowledge about stoma and stoma self-care practice among adolescent and adult patients with permanent stoma and its effect on their quality of life and self-care efficacy.

\section{Methods}

Design: A descriptive correlational cross-sectional design was utilized in this study.

Setting: The study was conducted at the Clinical Oncology and Nuclear Medicine Department and its relevant outpatient's clinic of Tanta Main University Hospital and Outpatient's clinic of General Surgical Department of Emergency Hospital at Tanta University, Tanta, Egypt.

Subjects: A convenience sample of 140 stoma patients; 70 adult and 70 adolescents, both genders who were visiting the previously mentioned setting post-surgery and during follow-up were interviewed. Inclusion criteria were being conscious with a permanent stoma, first year after surgery, have no post-operative complications (surgical site infection, anastomotic leakage) and no critical or co-morbid conditions.

Tools of data collections: The questionnaire for data collection included the following parts:

A. Socio-demographic characteristics: include patients' age, gender, marital status, education, occupation and previous training about self-care management of stoma.

B. Patients' clinical data: such as causes of stoma, smoking, time of surgery, received treatment and difficulty with self-care and self-care training.

C. Knowledge of stoma: This questionnaire included definition, causes, types, complication and risks of stoma (14 questions). Knowledge about stoma pouch such as types of pouch and appliance for stoma, criteria of changing pouch of stoma (14 questions). Knowledge about diet, fluid, physical activities and follow-up visits (14 questions). Response options included correct answer (1), don't' know or incorrect answer (0) with a total score of 42 . Total knowledge was categorized as good ( $\geq 70 \%)$, fair ( $69 \%$ to $50 \%)$ and poor $(<50 \%)$.

D. Knowledge of self-care practice: This questionnaire included preparation of the pouch, removal of the old pouch, daily care and cleaning of stoma and skin around the stoma, and applying the new pouch, empty the pouch (16 questions), stoma irrigation and hygienic care (17 questions). Response options for the knowledge of stoma self-care practice were done (1) and not done (0) with a total score of 33 that was categorized as satisfactory $(\geq 60 \%)$ and un-satisfactory $(<60 \%)$. Both knowledge of stoma and knowledge of stoma self-care practice were developed by the researchers after reviewing of the related literatures (Perry, et al., 2014; Black, \& Stuchfield, 2006; Gibson, \& Hardym, 2007; Stephenson, 2008; Baxter, Lloyd, 2004). It was piloted before data collection for content validity by 3 faculty members who are holding a $\mathrm{PhD}$ in nursing. The questionnaire was also tested for reliability before the main data analysis and reported a Cronbach's alpha of .85 .

E. A modified version of Stoma Quality of Life Scale (SQOL) Hunt and McKenna (1992). The scale was widely used to assess the quality of life of people with permanent stoma (Prieto, et al., 2005; Bond \& Fox, 2011; Dabirian, 2011). The scale consisted of 37 items with 5 subscales (psychological wellbeing, physical well-being, body image, sexual activity, and social concerns). The response option for the scale is 4-point; always (4), sometimes (3), rarely (2) and not at all (1). The total score of QOL was presented as good, fair and poor.

F. A modified version of Stoma self - Efficacy Scale, Bakkers et al., (1996). The scale composed of 13 items and was designed to assess the perceived self-efficacy and to predict coping with permanent stoma. Responses are categorized as not being confident at all (1), slightly confident (2), fairly confident (3), highly confident (4) and extremely confident (5). The total score was classified as positive self-efficacy $(>50)$ and negative self-efficacy $(<50)$.

3- A pilot study was carried out to test the study tools. It was conducted on $10 \%$ of the total sample size to test the feasibility and applicability of the tools and to determine any obstacles that may encountered during the period of data collection and needed modifications were done. The piloted patients were 
excluded from the study sample.

All Tools of data collection were translated into Arabic language because the study subjects had different levels of education. Data collection for this study was carried out over the period of five months at the beginning of January 2018 to the end of May 2018.

\section{Ethical consideration}

An official permission was obtained from the directors and the ethical committee at the study settings. Participants were informed about the study objectives, voluntary participation and the right to withdraw at any time from the study without any risk. Those who agreed to participate were asked to provide a written consent. Confidentiality and anonymity of participants were granted throughout the study.

\section{Procedure of data collection}

Patients were invited to participate in the study at the morning shift while they were waiting for the treatment or during follow up period at outpatient's clinics of the study settings. Each eligible participant was approached by the researchers, the objectives of the study were explained, the consent was obtained and data were collected from each participant in a private room. The interview for each participant lasted from 30 to 45 minutes. Due to the relatively lengthy questionnaire and for the special condition of the participants, the questionnaire was submitted separately, and a period of rest were provided for each participant.

\section{Results}

Regarding adolescents, descriptive statistics showed that $28.6 \%$ were in age group 13 to 16 and $71.4 \%$ in age group 16 to $21.56 \%$ were males and $44 \%$ females, $70 \%$ were singles and $30 \%$ married. $44 \%$ were students, $29 \%$ working and $27 \%$ were not working. Regarding education, $26 \%$ were illiterate, $11 \%$ had basic education, and $63 \%$ had secondary education.

Regarding the clinical data for adolescents, $16 \%$ were smokers and $84 \%$ were not. Cause of stoma were $47 \%$ cancer and 53\% abdominal trauma. The surgery was done within 1 to 6 months among $90 \%$ of the participants. $43 \%$ received chemotherapy and $57 \%$ radiotherapy as a treatment for their condition. $17 \%$ received self-care training about stoma and $83 \%$ did not and $57 \%$ reported having difficulty with self-care.

Regarding adults, descriptive statistics revealed that two thirds were in age group 31 to $60,50 \%$ were males and $50 \%$ females. $64 \%$ were married, and $27 \%$ divorced. $23 \%$ were illiterate, $20 \%$ had elementary education, $10 \%$ secondary school and $47 \%$ were university graduates. $44 \%$ working as workers, $33 \%$ employed in professional work, and $23 \%$ were not working. $21 \%$ got self-care training for stoma while $79 \%$ did not.

As for clinical data, $46 \%$ were smokers and $54 \%$ were not, $3 \%$ of stoma causes were cancer and $97 \%$ were abdominal trauma. $57 \%$ have done the operation within 1 to 6 months and $43 \%$ within one year. $26 \%$ received chemotherapy and 74\% radiotherapy, 79\% reported not receiving self-care training, $43 \%$ reported self-care difficulties while $57 \%$ reported no difficulty with self-care.

Demographic characteristics of the study sample is presented in table 1. 
Table 1: Socio-demographic characteristics of the study sample

\begin{tabular}{|c|c|c|c|c|}
\hline \multirow[t]{2}{*}{ Demographic characteristics } & \multicolumn{2}{|c|}{ Adolescents } & \multicolumn{2}{|c|}{ Adults } \\
\hline & $\#$ & $\%$ & $\#$ & $\%$ \\
\hline $\begin{array}{l}\text { Age } \\
\qquad \begin{array}{l}13-16 \\
16-21 \\
22-30 \\
31-60 \\
\text { More than } 60\end{array}\end{array}$ & $\begin{array}{l}20 \\
50\end{array}$ & $\begin{array}{l}28.6 \\
71.4\end{array}$ & $\begin{array}{r}23 \\
47 \\
- \\
\end{array}$ & $\begin{array}{r}33 \\
67 \\
- \\
\end{array}$ \\
\hline $\begin{array}{l}\text { Gender } \\
\text { Male } \\
\text { Female } \\
\end{array}$ & $\begin{array}{l}39 \\
31 \\
\end{array}$ & $\begin{array}{l}56 \\
44 \\
\end{array}$ & $\begin{array}{l}35 \\
35 \\
\end{array}$ & $\begin{array}{l}50 \\
50 \\
\end{array}$ \\
\hline $\begin{array}{l}\text { Marital Status } \\
\text { Single } \\
\text { Married } \\
\text { Divorced } \\
\text { Widow } \\
\end{array}$ & $\begin{array}{l}49 \\
21\end{array}$ & $\begin{array}{c}70 \\
30 \\
- \\
-\end{array}$ & $\begin{array}{c}45 \\
19 \\
6 \\
\end{array}$ & $\begin{array}{c}- \\
64 \\
27 \\
9\end{array}$ \\
\hline $\begin{array}{l}\text { Education } \\
\text { Illiterate } \\
\text { Basic } \\
\text { Secondary } \\
\text { University }\end{array}$ & $\begin{array}{c}18 \\
8 \\
44\end{array}$ & $\begin{array}{l}26 \\
11 \\
63 \\
-\end{array}$ & $\begin{array}{c}16 \\
14 \\
7 \\
33\end{array}$ & $\begin{array}{l}23 \\
20 \\
10 \\
47\end{array}$ \\
\hline $\begin{array}{l}\text { Occupation } \\
\text { Students } \\
\text { Workers } \\
\text { Professional } \\
\text { Not working }\end{array}$ & $\begin{array}{c}31 \\
20 \\
- \\
19 \\
\end{array}$ & $\begin{array}{c}44 \\
29 \\
- \\
27\end{array}$ & $\begin{array}{l}31 \\
23 \\
16 \\
\end{array}$ & $\begin{array}{l}- \\
44 \\
33 \\
23 \\
\end{array}$ \\
\hline Clinical data & & & & \\
\hline $\begin{array}{l}\text { Smoking } \\
\text { Yes } \\
\text { No } \\
\end{array}$ & $\begin{array}{l}11 \\
59 \\
\end{array}$ & $\begin{array}{l}16 \\
84 \\
\end{array}$ & $\begin{array}{l}32 \\
38 \\
\end{array}$ & $\begin{array}{l}46 \\
54 \\
\end{array}$ \\
\hline $\begin{array}{l}\text { Cause of stoma } \\
\text { Cancer } \\
\text { Abdominal Trauma }\end{array}$ & $\begin{array}{l}33 \\
37\end{array}$ & $\begin{array}{l}47 \\
53\end{array}$ & $\begin{array}{c}2 \\
68\end{array}$ & $\begin{array}{c}3 \\
97\end{array}$ \\
\hline $\begin{array}{l}\text { Time of surgery } \\
1 \text { to } 6 \text { months } \\
7 \text { months to } 1 \text { year }\end{array}$ & $\begin{array}{c}63 \\
7 \\
\end{array}$ & $\begin{array}{l}90 \\
10 \\
\end{array}$ & $\begin{array}{l}40 \\
30 \\
\end{array}$ & $\begin{array}{l}57 \\
43 \\
\end{array}$ \\
\hline $\begin{array}{l}\text { Treatment } \\
\text { Chemotherapy } \\
\text { Radiotherapy }\end{array}$ & $\begin{array}{l}30 \\
40 \\
\end{array}$ & $\begin{array}{l}43 \\
57 \\
\end{array}$ & $\begin{array}{l}18 \\
52 \\
\end{array}$ & $\begin{array}{l}26 \\
74 \\
\end{array}$ \\
\hline $\begin{array}{l}\text { Stoma self-care training } \\
\text { Yes } \\
\text { No }\end{array}$ & $\begin{array}{l}12 \\
58 \\
\end{array}$ & $\begin{array}{l}17 \\
83 \\
\end{array}$ & $\begin{array}{l}15 \\
55 \\
\end{array}$ & $\begin{array}{l}21 \\
79 \\
\end{array}$ \\
\hline $\begin{array}{l}\text { Self-care difficulty } \\
\text { Yes } \\
\text { No }\end{array}$ & $\begin{array}{l}12 \\
58 \\
\end{array}$ & $\begin{array}{l}17 \\
83\end{array}$ & $\begin{array}{l}30 \\
40 \\
\end{array}$ & $\begin{array}{l}43 \\
57 \\
\end{array}$ \\
\hline
\end{tabular}

\section{Knowledge of Stoma}

As reported in table 2, about two thirds of the adolescents reported fair knowledge and one third reported poor knowledge regarding definition, causes, types, complication and risks of stoma. On the other hands, $48 \%$ of the adults reported fair knowledge and $41 \%$ reported poor knowledge of stoma definition, causes, types, complication and risks of stoma.

More than half of the adolescents reported fair knowledge and more than one third reported good knowledge regarding stoma pouch, appliance for stoma, criteria of changing pouch of stoma portrayed. Fifty-eight percent of the adults reported good knowledge and $27 \%$ reported fair knowledge regarding this item. $64 \%$ of the adolescents and $50 \%$ of adults reported fair knowledge of diet, fluids and activity. In this regard, $18 \%$ of adolescents and $41 \%$ of adults reported good knowledge. Knowledge of self-care practice was presented as fair among $50 \%$ of the 
adolescents and $43 \%$ among adults. While good level of knowledge was reported among $52.9 \%$ of adults and $28.6 \%$ of adolescents for this item.

Chi square test of association showed that there is no statistical significance association between adolescents and adults regarding knowledge of definition, causes, types, complications and risks of stoma $\left(\mathrm{X}^{2}=1.67, \mathrm{p}=.79\right)$. No statistical significance association between adolescents and adults regarding knowledge of stoma \& stoma pouch, appliance for stoma, criteria of changing pouch of stoma $\left(\mathrm{X}^{2}=.681, \mathrm{p}=.95\right)$. In addition, there was no statistical significance association between adolescents and adults regarding knowledge of diet, fluids and activity $\left(\mathrm{X}^{2}=2.95, \mathrm{p}=.56\right)$, and knowledge of self-care practice $\left(\mathrm{X}^{2}=1.652, \mathrm{p}=.49\right)$.

Table 2: Levels of knowledge and association between adolescents and adults regarding stoma, stoma pouch and knowledge of stoma self-care.

\begin{tabular}{|c|c|c|c|c|c|c|c|c|}
\hline \multirow[t]{2}{*}{ Knowledge about stoma } & \multicolumn{3}{|c|}{$\begin{array}{c}\text { Adolescents } \\
\mathbf{N}=\mathbf{7 0}\end{array}$} & \multicolumn{3}{|c|}{$\begin{array}{c}\text { Adult } \\
\mathbf{N}=70\end{array}$} & \multirow[t]{2}{*}{$\mathrm{X}^{2}$} & \multirow[t]{2}{*}{$\begin{array}{c}\text { p- } \\
\text { value }\end{array}$} \\
\hline & $\begin{array}{l}\text { Good } \\
\#(\%)\end{array}$ & $\begin{array}{l}\text { Fair } \\
\#(\%)\end{array}$ & $\begin{array}{l}\text { Poor } \\
\#(\%)\end{array}$ & $\begin{array}{l}\text { Good } \\
\#(\%)\end{array}$ & $\begin{array}{l}\text { Fair } \\
\#(\%)\end{array}$ & $\begin{array}{l}\text { Poor } \\
\#(\%)\end{array}$ & & \\
\hline $\begin{array}{l}\text { Knowledge of definition } \\
\text { causes, } \\
\text { types, } \\
\text { complication and risks of } \\
\text { stoma }\end{array}$ & $5(7)$ & $43(61.4)$ & $22(31.4)$ & $7(10)$ & $34(48.6)$ & $29(41.4)$ & 1.67 & .79 \\
\hline $\begin{array}{l}\text { Knowledge of stoma \& } \\
\text { stoma pouch, appliance } \\
\text { for stoma, criteria of } \\
\text { changing pouch of stoma }\end{array}$ & $27(38.6)$ & $38(54.3)$ & $5(7)$ & $41(58.6)$ & $19(27)$ & $10(14.3)$ & .681 & .95 \\
\hline $\begin{array}{l}\text { Knowledge diet, fluid, } \\
\text { activity }\end{array}$ & $13(18.6)$ & $45(64)$ & $12(17)$ & $29(41.4)$ & $35(50)$ & $6(8.6)$ & 2.95 & .56 \\
\hline $\begin{array}{l}\text { Knowledge of self-care } \\
\text { practice }\end{array}$ & $20(28.6)$ & $35(50)$ & $15(21.4)$ & $37(52.9)$ & $30(43)$ & $3(4.3)$ & 1.652 & .49 \\
\hline
\end{tabular}

\section{Self-care practice of stoma:}

Table 3 display that two thirds of the adolescents reported satisfactory level of practice regarding stoma self-care practice (pouch change and peristomal skin care) while one third reported unsatisfactory level regarding the same item. In addition, $71 \%$ of the adolescents reported unsatisfactory level of practice regarding stoma irrigation and hygienic care.

Adults on the other hand showed a satisfactory level of self-care practice of stoma as $81.4 \%$ reported satisfactory level of practice regarding stoma care (pouch change and peristomal skin care) and $67 \%$ reported satisfactory level of practice of stoma irrigation and hygienic care

Chi square was also performed to test the association between adolescents and adults regarding stoma selfcare practice. Results displayed that there were no statistical significance association between adolescents and adults regarding self-care practice of stoma care (pouch change and peristomal skin care), $\mathrm{X}^{2}=3.616, \mathrm{p}=.46$ while there were statistical significance association between adolescents and adults regarding self-care practice of stoma irrigation and hygienic care, $\mathrm{X}^{2}=3.269, \mathrm{p}=.03$.

Table 3: Levels of stoma self-care practice among adolescents and adults

\begin{tabular}{|c|c|c|c|c|c|c|}
\hline \multirow[t]{2}{*}{$\begin{array}{l}\text { Self-care practice } \\
\text { regarding stoma }\end{array}$} & \multicolumn{2}{|c|}{$\begin{array}{c}\text { Adolescents } \\
N=70\end{array}$} & \multicolumn{2}{|c|}{$\begin{array}{l}\text { Adult } \\
\mathbf{N}=\mathbf{7 0}\end{array}$} & \multirow[t]{2}{*}{$\mathrm{X}^{2}$} & \multirow[t]{2}{*}{$\begin{array}{l}\text { p- } \\
\text { value }\end{array}$} \\
\hline & $\begin{array}{l}\text { Satisfactory } \\
\#(\%)\end{array}$ & $\begin{array}{l}\text { Unsatisfactory } \\
\#(\%)\end{array}$ & $\begin{array}{l}\text { Satisfactory } \\
\#(\%)\end{array}$ & $\begin{array}{l}\text { Unsatisfactory } \\
\#(\%)\end{array}$ & & \\
\hline $\begin{array}{l}\text { Self-care practice of } \\
\text { stoma care (pouch change } \\
\text { and peristomal skin care) }\end{array}$ & $47(67)$ & $23(33)$ & $57(81.4)$ & 13 (18.6) & 3.616 & .46 \\
\hline $\begin{array}{l}\text { Self-care } \\
\text { stoma practice of } \\
\text { store } \\
\text { irrigation and hygienic } \\
\text { care) }\end{array}$ & $20(28.6)$ & $50(71.4)$ & 47 (67) & $23(33)$ & 3.269 & .03 \\
\hline
\end{tabular}

\section{Quality of life and stoma self-efficacy}

As presented in table 4, 100\% of adolescents showed fair total quality of life with $100 \%$ fair quality of physiological life, $88.6 \%$ fair quality of psychological life, $93 \%$ fair quality of sexual life, $87 \%$ fair quality of social life and $80 \%$ quality of body image respectively.

On the other hand, $54.3 \%$ of adults reported fair and $45.7 \%$ reported good total quality of life. Majority ( $80 \%)$ 
portrayed fair social quality of life, similar percentages of adults showed fair $(58.6 \%)$ and good (41.4\%) psychological quality of life, good (55.7\%) and fair (44.3\%) physiological quality of life. More than half of the adults showed fair body image $(58.6 \%)$ and sexual quality of life $(57 \%)$ respectively.

Regarding stoma self-efficacy, $88.6 \%$ of adolescents showed negative self-efficacy and $11.4 \%$ showed positive self-efficacy. In the same context, $93 \%$ of adults reported positive self-efficacy while $7 \%$ reported negative stoma self-efficacy.

Chi square test showed that there were statistically significant association between adolescents and adults regarding total QOL $\left(\mathrm{X}^{2}=2.563, \mathrm{p}=.003\right)$, psychological QOL $\left(\mathrm{X}^{2}=3.432, \mathrm{p}=.002\right)$, physiological QOL $\left(\mathrm{X}^{2}=\right.$ $2.632, \mathrm{p}=.001)$, body image $\left(\mathrm{X}^{2}=1.642 . \mathrm{p}=.04\right)$, social QOL $\left(\mathrm{X}^{2}=.384, \mathrm{p}=.04\right)$. There was no statistical significance association between adolescents and adults regarding sexual QOL $\left(\mathrm{X}^{2}=1.626, \mathrm{p}=.57\right)$.

In addition, there was statistically significant association between adolescents and adults regarding selfefficacy $\left(\mathrm{X}^{2}=.2 .321, \mathrm{p}=.002\right)$.

Results of quality of life, self-efficacy and association between adolescents and adults are presented in table 4.

Table 4: Quality of life, self-efficacy and association between adolescents and adult

\begin{tabular}{|c|c|c|c|c|c|c|c|c|}
\hline \multirow[t]{2}{*}{ Quality of life } & \multicolumn{3}{|c|}{ Adolescents } & \multicolumn{3}{|c|}{ adult } & \multirow[b]{2}{*}{ Chi } & \multirow[b]{2}{*}{$\begin{array}{l}\text { p- } \\
\text { value }\end{array}$} \\
\hline & $\begin{array}{l}\text { Good } \\
\#(\%)\end{array}$ & $\begin{array}{l}\text { Fair } \\
\#(\%)\end{array}$ & $\begin{array}{l}\text { Poor } \\
\#(\%)\end{array}$ & $\begin{array}{l}\text { Good } \\
\#(\%)\end{array}$ & $\begin{array}{l}\text { Fair } \\
\#(\%)\end{array}$ & $\begin{array}{l}\text { Poor } \\
\#(\%)\end{array}$ & & \\
\hline $\begin{array}{l}\text { Psychological } \\
\text { QOL }\end{array}$ & $1(1.4)$ & $62(88.6)$ & $7(10)$ & $29(41.4)$ & $41(58.6)$ & 0 & 3.432 & .002 \\
\hline $\begin{array}{l}\text { Physiological } \\
\text { QOL }\end{array}$ & 0 & $70(100)$ & 0 & $39(55.7)$ & $31(44.3)$ & 0 & 2.632 & .001 \\
\hline Body image & 0 & $56(80)$ & $14(20)$ & $23(32.9)$ & $41(58.6)$ & $6(8.5)$ & 1.642 & .04 \\
\hline Sexual QOL & 0 & $65(93)$ & $5(7)$ & $25(35.7)$ & $40(57)$ & $5(7)$ & 1.626 & .57 \\
\hline Social QOL & 0 & $61(87)$ & $9(13)$ & $13(18.6)$ & $57(81.4)$ & 0 & .384 & .04 \\
\hline \multirow[t]{2}{*}{ Total QOL } & 0 & $70(100)$ & 0 & $32(45.7)$ & $38(54.3)$ & 0 & 2.563 & .003 \\
\hline & \multicolumn{3}{|c|}{ Adolescents } & \multicolumn{3}{|c|}{ Adults } & & \\
\hline \multirow{2}{*}{$\begin{array}{l}\text { Stoma self- } \\
\text { efficacy }\end{array}$} & \multirow{2}{*}{\multicolumn{2}{|c|}{$\begin{array}{c}\text { Positive } \\
11.4 \%\end{array}$}} & Negative & \multirow{2}{*}{\multicolumn{2}{|c|}{$\begin{array}{c}\text { Positive } \\
93 \%\end{array}$}} & Negative & \multirow[b]{2}{*}{2.321} & \multirow[b]{2}{*}{.002} \\
\hline & & & $88.6 \%$ & & & $7 \%$ & & \\
\hline
\end{tabular}

Independent sample t-test was conducted to text if there is a relationship between demographic variables such as age, gender, marital status, education and the study variables; knowledge of stoma, knowledge of stoma selfcare practice, self-efficacy and QOL. Results showed that age, knowledge of selfcare practice and self-efficacy reported significance association with QOL as presented in table 5.

Table 5: Independent t-test between demographics, knowledge of stoma, knowledge of self-care practice and self-efficacy and QOL among the study samples

\begin{tabular}{|l|c|c|}
\hline Demographics and study variables & \multicolumn{2}{|c|}{ QOL } \\
\hline Age & -1.506 & $\mathbf{. 0 0 0}$ \\
\hline Gender & -2.089 & .38 \\
\hline Marital status & 3.751 & .45 \\
\hline Education & -.135 & .27 \\
\hline Knowledge of stoma & 2.467 & .23 \\
\hline Knowledge of self-care practice & 5.954 & $\mathbf{. 0 0 2}$ \\
\hline Positive self-efficacy & 2.207 & $\mathbf{. 0 0 1}$ \\
\hline
\end{tabular}

\section{Discussion}

The current study aimed at assessing the level of knowledge of stoma and stoma self-care practice and their relationship to self-care efficacy and QOL among adolescents and adults with permanent stoma. High percentage of adolescents and considerable percentage of adults reported fair and poor level of knowledge in all the knowledge questionnaire items. These variations did not provide statistical significance differences among the 2 groups. This result was supported by previous works of Kumer (2016; Ran, et al, 2016; Cheng et al. 2013). The possible reasons for lack of knowledge among participants in this study would be due to their demographic characteristics. One quarter of both groups were illiterate, and majority did not receive any training for the stoma that would have raised their awareness. Adults reported a pit higher level at some aspects of knowledge than adolescents. This variation would be because of the majority of the adults were university graduates who are working in professional work. Such factors would contributed to variations of level of knowledge.

Stoma self-care practice was satisfactory among adults and unsatisfactory among adolescents especially for stoma irrigation. This piece of result was supported by Cheng et al (2013; Parker, 2012). Adults in our study were 
well educated, have professional jobs, have established their families and can manage their care independently. Adolescents are more likely to be dependent on someone else in their families to care of them. That is supported by the fact that majority of adolescents in this study reported not having difficulty with self-care.

Adolescents reported fair total QOL and all the subscales while considerable percentage of adults reported levels of good and fair of total QOL and all subscales. There were statistically significant association between adolescents and adults regarding all QOL subscales except for sexual aspect which could be due to cultural issues. In addition, age knowledge and self-efficacy reported association with QOL. Adults and those with positive selfefficacy showed better QOL. Self-efficacy is the learned ability to perform self-care and is influenced by many factors such as knowledge and readiness. This was congruent with many previous researches who indicated that self-efficacy is a predictor of psychological and physiological wellbeing among patients with stoma. (Mohamed et al., 2017; Culha, \& Bolluk, 2016, Pandey \& Dhungana, 2013. Kit-Man et al., 2007; Lai \& Kin, 2014).

Adolescents and adults in this study reported fair and good satisfaction with sexual QOL and there was no statistical association between them. This was not consistence with Liao \& Qin (2016; Neuman, et al., 2011) who reported that sexual activity was a concern for their sample. Participants from this study either adolescents or adults had their stoma initiated with 6 months. At this stage of recovery, the focus is more on adaptation to the stoma as a huge change in their life and body rather than sexual activity that might be obvious later. Stoma related concerns also would be different for cultural reasons.

\section{Conclusion and Recommendations:}

The current study provided an evidence of unsatisfactory level of knowledge and self-care practice among adolescents and adults patients with permanent stoma. This in turn affected QOL and self-efficacy among this kind of patients. To provide a holistic care for such patients, assessment of all aspects related to stoma are important to deliver individualized and appropriate care that improve QOL and enhance self-efficacy among patients with colostomy. The current study displays the actual needs of these type of patients, further educational studies are needed with larger and randomly selected samples. The need for qualitative approach to further and deeply explain the lived experience of patients with permanent stoma is important to uncover factors that is hard to be explained in a quantitative method.

\section{Acknowledgement}

The researchers are grateful to all the patients who participated in this study

\section{Reference}

Abo El-Fadl, S., Abdel Aal, 1 \& Hussan, A. (2013). Sexual and Psychological Adverse Events (AE) Facing Stoma patients in our society, Life Science Journal 2013, 10(4), 952. .

Bandura A. Self-efficacy: Toward a unifying theory of behavioral change. Psychological Review. (1977), 84, 191215.

Bartle C, Darbyshire M, Gaynor P, Hassan C, Whitfield J. Addressing common stoma complications. Nursing \& Residential Care. 2013; 15(3).

Baxter A, Lloyd, P.A. (2004). Elimination: stoma care. In Dougherty L, Lister S (Eds) The Royal Marsden Hospital Manual of Clinical Nursing Procedures. Sixth edition. Blackwell Publishing, London, 316-329.

Bekkers, M. Van- knippenberg, F., Van Den -Borne, H. \& Van Berger-Henegouwen, G. (1996). Prospective Evaluation of Psychosocial Adaptation to Stoma Surgery: The Role of Self-Efficacy. Psychosomatic Medicine, 58, 183-191.

Black, P. \& Stuchfield, B (2006). Multicultural stoma care. In: Caring for stoma patients, best practice guidelines. Clinical Medicine Ltd., High Wycombe.

Bond, T. \& Fox, C. (2011). Applying the Rasch Model: Fundamental Measurement in the Human Sciences. Lawrence Erlbaum Associates Publishers. Mahwah, New Jersey; 7-34.

Calvert, S., Disley, H. and Jowett, A. Stoma care clinical nursing standards. 3rd ed., Securi Care, Stoma Care Clinical Nursing Standards. www.securicare medical.com. UK, 2012.

Carlsson, E., Berndtsson, I., Hallen, A., Lindholm, E. \& Persson, E. (2010). Concerns and quality of life before surgery and during the recovery period in patients with rectal cancer and an ostomy. Journal of Wound, Ostomy and Continence Nursing, 37:654-661.

Cheng, F., Meng, A., Yang, L., Zangh, Y. (2013). The Correlation Between Ostomy Knowledge and Self-Care Ability with Psychosocial Adjustment in Chinese Patients with a Permanent Colostomy: A Descriptive Study. Ostomy/wound management 59(7):35-38.

Culha, I, Kosgeroglu, N. \& Bolluk, O. (2016). Effectiveness of Self-care Education on Patients with Stomas, IOSR Journal of Nursing and Health Science, 5(2): 70-76.

Dabirian, A., Yaghmaei, F., Rassouli, M. \& Tafreshi, M. (2011). Quality of life in ostomy patients: a qualitative Study, Patient Preference and Adherence, 5, 1-5. 
De Sousa, M. J., Andrade, S. S., de Brito, K., Matos, S. D., Coelh, S. H. and Oliveira, S. F. (2016). Sociodemographic and clinical features and quality of life in stomized patients. Journal of coloproctol, 3 6(1), 27-33. .

El Sayed S., Abd Elhameed S., Hassanen A. Effect of nursing stoma care training on geriatric patients' self-esteem and psychological status, IOSR Journal of Nursing and Health Science, 2018; 7(4): 52-62.

Gibson, P. \& Hardy, L (2007). Cumbria Competence and Training: Assisting clients with stoma management. Cumbria Changing Workforce Project.

Grant, M., Ferrell, B., Dean, G. Uman, G., Chu D. \& Krouse, R. (2004). Revision and psychometric testing of the City of Hope Quality of Life- Ostomy Questionnaire. Quality of Life Research, 13, 1445-1457.

Hunt S. \& McKenna S. The QLDS: a scale for the measurement of quality of life in depression. Health Policy 1992, 22:307-319.

Kit-Man, W. H., Janita Pak-Chun, C., P., Twinn, S., (2007). Self-efficacy and Quality of Life Among Stoma Patients in Hong Kong. Cancer Nursing, 30 (3), 186-193.

Laio, C \& Kin, Y. (2014) Factors Associated with Stoma Quality of Life among Soma Patients International Journal of Nursing Sciences 1(2), 196-201.

Marquis, P., Marrel, A. \& Jambon, B. (2003). Quality of life in patients with stomas: The Montreux Study. Ostomy and Wound Management, 49, 48-55.

Mohamed, A.S., Nasr El-Din, A., Mohamed, F.M. (2018). Effect of Educational Guideline on Quality of Life and Self Efficacy for Adult and Adolescent Patients with Colostomy. International Journal of Novel Research in Healthcare and Nursing, 5 (1), 106-121.

Mohamed, S., Salem, G.M., Mohamed, H. A. (2017). Effect of Self-care Management Program on Self-efficacy among Patients with Colostomy. American Journal of Nursing Research. 2017, 5(5), 191-199.

National Cancer Institute (NCI).: Ostomy clinic care. Available at: http://www.nci.nih.gov. Accessed on: $11 / 5 / 2016$.

Pandey, R.A., \& Dhungana, S. G. (2013). Knowledge and practice of stoma care among ostomates at b.p.koirala memorial cancer hospital, Journal of Nobel Medical College, 4(1), issue 7, 36: 45.

Parker, M. 92012). Caring for vulnerable ostomists: Learning Disabilities and Stoma Care. British Journal of Nursing, 21(16), S4-S8.

Perry, A.G., Potter, P.A., Ostendorf, W. (2014). Ostomy care. In: Perry AG, Potter PA, Ostendorf W, eds. Clinical Nursing Skills and Techniques. 8th ed. Philadelphia, PA: Elsevier Mosby; 2014: chap 35.

Prieto L., Thorsen, H. \& Juul, K. (2005). Development and validation of a quality of life questionnaire for patients with colostomy or ileostomy, Health and Quality of Life Outcomes, 3, 62.

Putri, A., Dahlia, D., Sitorus, R., \& Maria, R. (2018). Relationship between the Knowledge on Self-Efficacy about Counseling and Stoma Site Marking for Patients Undergoing Stoma Surgery. The Malaysian Journal of Nursing, 9(3), $54-60$.

Ran, L., Jiang, X., Qian, E., Kong, H. \& Wang, X. (2016). Quality of life, self-care knowledge access, and selfcare needs in patients with colon stomas one-month post-surgery in a Chinese Tumor Hospital. International Journal of Nursing Sciences, 3, 252-258.

Recalla S1, English K, Nazarali R, Mayo S, Miller D, Gray M. (2013). Ostomy care and management: a systematic review. Journal of Wound, Ostomy and Continence Nursing. 40(5),489-500.

Salomé, G.M., De Almeida, S.A., Silveira, M.M. (2014). Quality of life and self-esteem of patients with intestinal stoma. Journal of Coloproctol, 34(4), 231-239.

Sasaki, V.D., Pereira, A., P., Ferreira, A. M., Pinto, M.H., \& Gomes, J. J. (2012). Health care service for ostomy patients: profile of the clientele. Journal of Coloproctol, 32(3): 232-239.

Stephenson, N (2008). Self-directed learning: communication. British Journal of Healthcare Assistants, 2(6), 301303.

Taylor, J., Crodes, W., Parker, M., Watts, J. and Whitehead, D. (2012). Guideline for care of a patient with a stoma. Nottingham University Hospitals NHS trust, supporting policy, working in new ways package. 